\title{
Post-Operative Computed Tomography to Evaluate the Accuracy of Thoracic and Lumbosacral Spine Pedicular Screw Fixation
}

\author{
Saif M.Kani* \\ CABOS \\ Ali Bakir. Al-Hilli** \\ FIBMS \\ Dawood S. Al-Obidi** \\ FRCS
}

Abstract:

Background: pedicular screw fixation is rapidly becoming a widely used method of spinal instrumentation. Despite improvement in design of instruments and surgical technique and the use of intra-operative fluoroscopy, pedicle cortical perforations occur endangering nearby neurovascular or extra vertebral structures.

Objective: This is a prospective (consecutive cases study) designed for Evaluation of incidence of pedicle screw misplacement in our study sample, compare our results to what is published in literature.

JFac Med Baghdad Patients and Method: This study involved 25 adult patients ( 10 males and 15 females ) their age ranged

between ( 18 and 70 years) who underwent spinal surgery with pedicle screw fixation for different
disorders of thoracic and lumbosacral spine with the aid of intraoperative fluoroscopy. Computed Tomography (CT) scan within one month was done for all patients to evaluate the accuracy of pedicle screw placement. Any new neurological symptoms was recorded and correlated with screw misplacement.

Results: 122 screws inserted in 25 patients with an overall accuracy of (90.16\%), frank misplacement of $(4.09 \%$ ) and questionable penetration of $(5.73 \%)$, new neurological deficit was seen in $(20 \%)$ among all misplaced screws and in one case (4\%) out of the 25 cases.

Conclusion: pedicle screw fixation surgery is a demanding procedure. Our incidence of screw misplacement is compatible with the lower published results in the literature. Not all patients with frank penetration of the pedicle cortical outlines developed complications.

Keywords: Computed tomography, Pedicular Screw fixation, accuracy.

\section{Introduction:}

Segmental pedicular screw fixation is rapidly becoming a widely used method of spinal instrumentation. However, pedicular screw systems represent difficult surgical techniques involving several potential problems and complications. Only by detailed knowledge of the anatomy of the spine, with clear understanding of the pedicular screw systems implementation, can the risks of complications be minimized.1the indications to perform a lumbosacral fusion and the subsequent clinical outcomes are topics of debate till today. The use of instrumentation to reduce the need for post operative external immobilization and bed rest through immediate stabilization of the spine is attractive, and the use of instrumentation by its self may improve the fusion rate. 2 Carefully applied pedicular screw fixation does not produce severe or frequent complications. Training in the pedicular screw application should be standard in orthopedic training programs since pedicular screw fixation represents the so-called gold standard of spinal internal fixation.3Pedicular screw fixation has the additional benefits of generally not requiring the presence of intact laminae, facet joints or spinous processes.4Pedicular screw has the benefit of fixing

* Orthopedic surgery, medical city, Baghdad. Ali.alhilli@yahoo.com

**Department of surgery, college of medicine, university of Baghdad. the whole 3 columns of the spine in comparison to sublaminar hooks or wires that provide fixation of only the posterior column.5However, despite improvements in the design of the instruments and surgical techniques and the use of intra-operative fluoroscopy, pedicle cortical perforations may occur, resulting in impingement of the adjacent neural or extra vertebral structures.

\section{Patients and methods:}

From June 2011 to July 2012 in the hospital of surgical specialties and nursing home hospital in medical city complex, a prospective type of study was conducted involving 25 consecutive adult patients underwent spinal surgery with the use of pedicular screw fixation system for different disorders of the thoracic and lumbosacral spine. Their age ranged between 18 and 70 years , including 10 male patients and 15 female patients. We had excluded patients with: Congenital and developmental anomalies of the spine, Patients with previous surgeries on the involved spinal segments, and Patients with medical or neurological disorders causing polyneuropathy and myopathy. All patients are informed about their involvement in the study and verbal and written consent ware taken from them, and then assessed clinically before the operation by taking detailed history and doing proper physical and neurological examination. Preoperative radiographs anteroposterior (AP) and lateral (L) views are taken to all patients before 
surgery, and Preoperative CT scan and MRI are taken according to clinical indications and our clinical decision and preoperative planning. All surgeries are performed by senior surgeons experienced in spine surgery and in the same centers where this study is conducted. All surgeries are done under general anesthesia, in prone position. The spinal level at which the operation to be performed is determined by using the anatomical surface landmarks and radiologically with the aid of image intensifier. A standard posterior approach was used in all cases. The screw entry point was identified by using the anatomical landmarks locating the intersection of the spine of the transverse process with the corresponding facet. The trajectory of the screw was checked using the Lateral and Anteroposterior projections with an intra-operative image intensifier. Within the first 2 days postoperatively full neurological assessment is done to detect any suspicious neurological signs like undue backache, new radicular symptoms or neurological deficit. Anteroposterior and Lateral plain radiographs were taken to all patients to record the position of the screws. Post-operative CT scan ( $3 \mathrm{~mm}$ axial slices) was performed in all 25 patients to evaluate the implant position within the first month after surgery. All accuracy evaluations were performed by both a radiologist who does not know any information about the techniques used for insertion of the screws and by the same surgical team conducted the procedure. Screw placement was considered correct when the screw was completely surrounded by the pedicle and no portion of the screw perforated outside the pedicle cortex. Questionable or (encroachment) when the pedicle outlines cannot be seen clearly and frank penetration of the pedicle: if the screw threads are perforated outside the pedicle cortical outlines. If the penetration of the pedicle screw was $2 \mathrm{~mm}$ or more along the pedicle inferiorly, superiorly, laterally, or medially, or anywhere from the corpus, it was assessed as misplaced. Penetration was further subdivided based on the measurement of the distance that the edge of the screw thread extended outside the pedicle cortex into (figure 1$)^{4}$ : minor $(\leq$ $2.0 \mathrm{~mm})$, moderate $(2.1-4 \mathrm{~mm})$, and severe $(>4 \mathrm{~mm})$. Any patient who developed new neurological manifestations in the misplaced or correct pedicle screws were assessed by MRI to ascertain the screw position and its relation to the neurological structures nearby. A prospective ( consecutive cases) study was done involving the study group , all data were collected and analyzed with SPSS 16 and Microsoft Office Excel 2007 , continuous data were expressed as Mean and SEM ( standard error of mean), while the nominal variables were expressed as numbers (\%) and plotted in tables and charts.

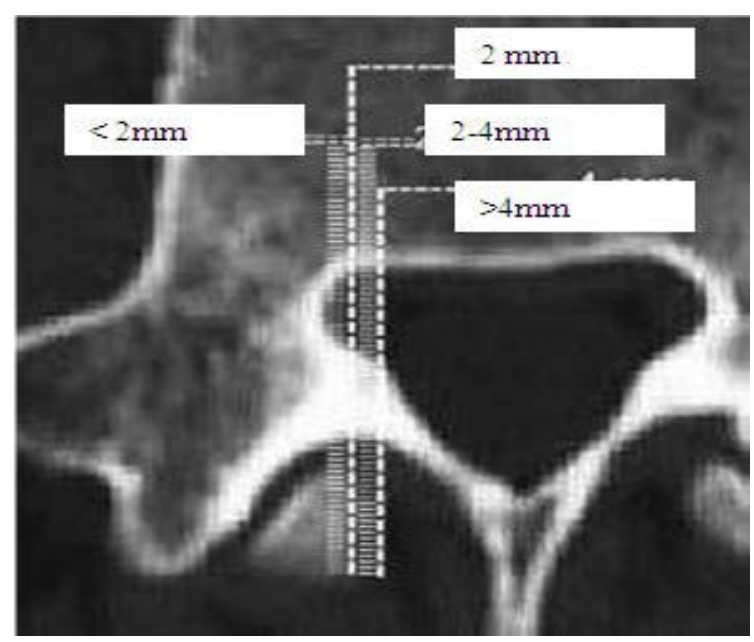

Figure1 axial CT view showing the measurements ranges for medial pedicle wall perforation by the aid of the measuring scale on CT image.

\section{Results:}

we reviewed the post-operative CT scans of consecutive cases involving 25 patients, their age ranged between 18 years and 70 years ( mean 44 years), 10 male patients( $40 \%$ ) and 15 female patients $(60 \%)$ (table1), who underwent posterior spinal fixation with the use of pedicular screw fixation system, involving levels extending from D11 to S1 vertebrae with a total of 122 inserted screws in which 62 screws were inserted in trauma cases, 48 screws in degenerative disk disease of the spine, and the remaining 12 screws were inserted in cases with spondylolithesis. Majority of our cases were trauma cases 14 out of 25 cases $(56 \%)$, while the degenerative disk diseases were 8 cases out of 25 cases $(32 \%)$ and least common indication for fixation was spondylolithesis in our study 3 cases ( $12 \%), 2$ of them were spondylolithesis at ( L4-L5 ) and are symptomatic grade 1, and the other one was ( L5S1)which was symptomatic grade 2 .

Table 1 distribution of 25 patients involved in the study according to their gender, age and indication for surgery

\begin{tabular}{llll}
\hline $\begin{array}{l}\text { Indication for } \\
\text { fixation }\end{array}$ & $\begin{array}{l}\text { Number of } \\
\text { cases, \%)( }\end{array}$ & Male/female & $\begin{array}{l}\text { Mean } \\
\text { age(years) }\end{array}$ \\
\hline Trauma & $14(56 \%)$ & $8 / 6$ & $35.35 \mathrm{y}$ \\
\hline $\begin{array}{l}\text { Degenerative } \\
\text { disk diseases }\end{array}$ & $8(32 \%)$ & $2 / 6$ & $56.62 \mathrm{y}$ \\
\hline Spondylolisthesis & $3(12 \%)$ & $0 / 3$ & $52.33 \mathrm{y}$
\end{tabular}

In our study the most commonly fixed level was L4 in which 26 screws inserted in it out of 122 screws $(21.31 \%)$, followed by L5 level in which 24 screws inserted $(19.67 \%)$ and the least commonly fixed level was D11 in which only 2 screws inserted in our study(1.63\%). Post-operative CT scans were done within one month of the surgery so that the patient will become easily ambulatory with less pain.Evaluation of the accuracy by the radiologist and the surgical team conducted the surgeries was done. In our series we found that out of 122 pedicular screws inserted for different clinical 
conditions in 25 cases, 5 screws (4.09\%) were considered to be malpositioned i.e. (frank penetration), and 7 screws $(5.73 \%)$ were considered to be questionable due to inability to clearly identify the cortical outline of the pedicle, while the remaining 110 screws $(90.16 \%)$ were considered to be correctly positioned (figure 2 ),

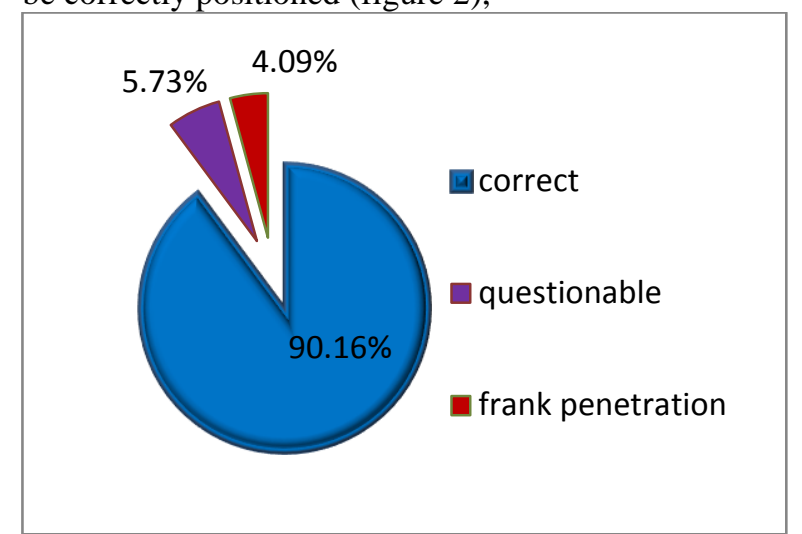

Figure 2 percentile distributions of the pedicular screws inserted in the study according to the accuracy of insertion.

From these 5 malpositioned screws 2 screws (40\%) were perforated the lateral cortex, and 2 other screws $(40 \%)$ were perforated the medial cortex, while only 1 screw $(20 \%)$ was penetrating the anterior vertebral body cortical outlines (table 2 ).

Table 2 Distribution of 5 malpositioned screws according to the direction of penetration of pedicular cortical outlines.

Direction of pedicular screw Number of screws out of 5 penetration and (\%)

\begin{tabular}{ll}
\hline Lateral wall penetration & $2(40 \%)$ \\
\hline Medial wall penetration & $2(40 \%)$ \\
\hline
\end{tabular}

Anterior body penetration $1(20 \%)$

With regard to the severity of pedicular screw perforation we found that out of the 5 screws that are malpositioned 4 screws $(80 \%)$ were in the category (mild) penetration with less than or equal to $2 \mathrm{~mm}$ out of the pedicle cortical outlines, 1 screw $(20 \%)$ in the (moderate) category with $2-4 \mathrm{~mm}$ penetration and no screws $(0 \%)$ in the (severe) penetration group( table 3).

Table 3: Distribution of the malpositioned screws according to the vertebral levels and characteristics of these malpositions (severity and direction).

\begin{tabular}{llll}
\hline $\begin{array}{l}\text { Vertebral } \\
\text { level fixed }\end{array}$ & $\begin{array}{l}\text { Number } \\
\text { of } \\
\text { screws }\end{array}$ & $\begin{array}{l}\text { Frank penetration } \\
\text { (number, severity, } \\
\text { direction) }\end{array}$ & $\begin{array}{l}\% \text { of } \\
\text { misplacement } \\
\text { out of total } \\
122 \text { screws }\end{array}$ \\
\hline D11 & 2 & 1, moderate,medial,Rt. & $0.81 \%$ \\
\hline D12 & 14 & 0 & $0 \%$ \\
\hline L1 & 12 & 0 & $0 \%$ \\
\hline L2 & 16 & 0 & $0 \%$ \\
\hline L3 & 14 & 1, mild, lateral, Lt. & $0.81 \%$ \\
\hline L4 & 26 & $\begin{array}{l}2:(1, \text { anterior) } \\
\text { (1, mild, lateral, Rt.) }\end{array}$ & $1.63 \%$ \\
\hline L5 & 24 & 1, mild, medial, Lt. & $0.81 \%$ \\
\hline S1 & 14 & 0 & $0 \%$ \\
\hline
\end{tabular}

N.B: Rt (right), Lt (left).
Further evaluation of these malpositioned screws done post operatively by proper clinical examination to detect any undue neurological deficit and we found that for the screw that is considered to be anteriorly penetrated no special intra operative or post-operative findings were detected and it has been documented by the CT scan that just the tip of the screw was out of the anterior confines of L4 vertebra and it was away from the major vessels. Form all the malpositioned screws only one screw (20\%) in one case $(4 \%)$ the one in D11 with moderate medial penetration was associated with new postoperative back pain with radiation to the right lower limb and the patient was lost for follow up ( figure 3,4,5).

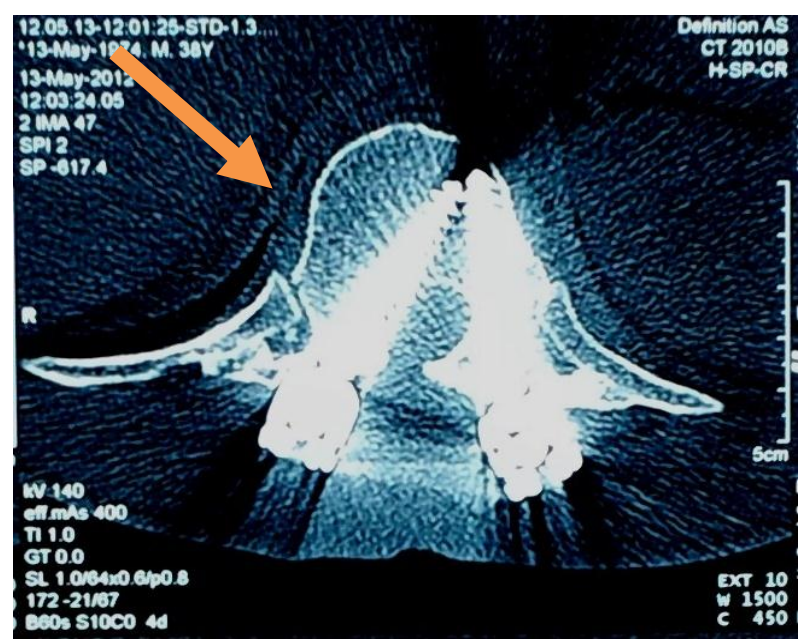

Fig.3.moderate right medial cortical penetration of D11 vertebral level.

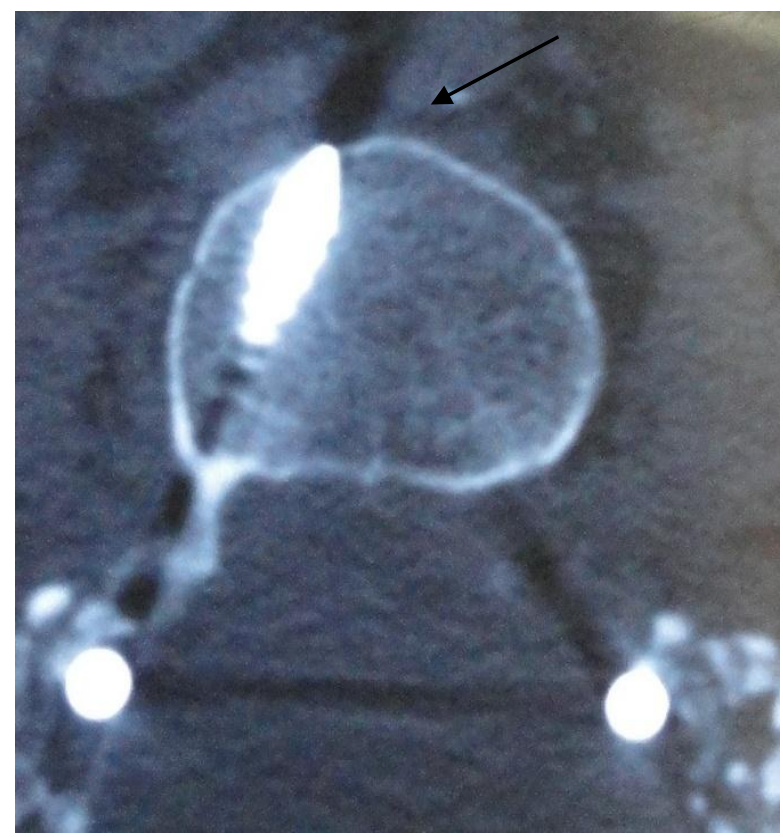

Fig.4.mild anterior penetration of vertebral body L4 level. 


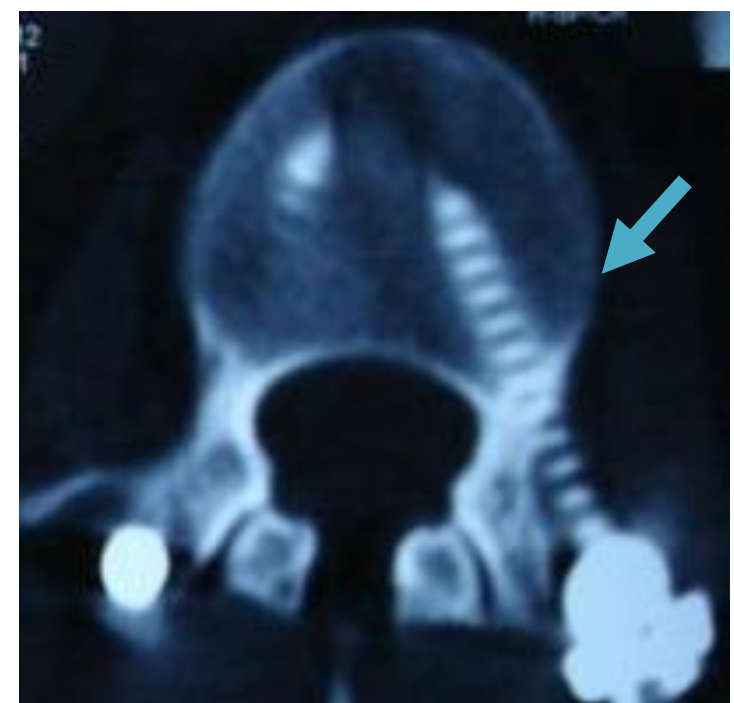

Fig.5. mild left lateral penetration of $L 3$ vertebral level.

\section{Discussion:}

Controversy has surfaced regarding the use of pedicular screws and their potential complications.5Comparing pedicular screws, wires, and hooks the highest incidence of symptomatic impingement occurs with pedicular screws, with a root injury or irritation occurring in a reported 3.2\% of cases6 .Pedicular screw insertion resulting in neurological deficit is rare, but may be due to faulty placement of screws, with perforation of the cortex and impingement of adjacent neural structures. Despite improvement in the design of instruments and attention to insertion techniques, cortical perforation does occur. Because many transgressions are asymptomatic, the true incidence is not known. Roy-camille et al reported in their experience that $10 \%$ of screws were not completely in the pedicle.7Pedicle screws that perforate the pedicle cortex may increase the risk of dural tearing, neurological damage and vascular or visceral damage8 . More over such screw malpositioning may result in loss of fixation, especially if it occurs at the lower end of the construct. Therefore proper placement of pedicular screws is important not only for prevention of neurological injury but also for maintenance of long term spinal stability9 .Since their introduction, the accuracy of placing pedicular screws has been the subject of many reported studies from which a wide range of screw malposition rates have resulted 10 .The rate influenced by a number of factors, including the post-operative assessment methods (conventional radiography versus CTscan). The term misplacement has been variously used for simple evidence of cortex breach or for frank misplacement in the spinal canal or in the extra vertebral tissues. Many authors consider placement inadequate in all screws with errors of $>2 \mathrm{~mm}$. others use the term encroachment or questionable to indicate minimal or (doubtful) cortical perforation 11,12 . In a recent study, misplacement was also defined as the central axis of the screw being outside the outer cortex of the pedicle wall as seen in axial CT images13 .Many studies have demonstrated that $\mathrm{CT}$ is more accurate than conventional radiographs in determining pedicular screw location and the difference is most striking in medially misplaced screws, with CT scan depicting 8-10 times as many frank or questionable penetration of pedicle cortex as conventional radiography 14 . In our study we obtained CT scan post operatively within one month for all patients exposed to pedicle screw fixation surgery, and this one month lag period had been chosen so that the patient will become more pain free and easily ambulating. An overall rate of pedicle perforation (misplacement) of $4.09 \%$ had been detected, the rate of mild penetration was $80 \%$, moderate penetration severity $20 \%$, and severe penetration of $0 \%$. Questionable or (doubtful) cortical perforation was noticed to be of $(5.73 \%)$, and in this group of questionable screws it was difficult to delineate exactly whether the screw had penetrated the cortical outlines or not because of the effect of what is called the blooming artifact of the screw metal in CT scan images, this artifact had put us in some cases in a situation that is difficult to say exactly whether the screw had really penetrated the cortical outlines or not so these screws had been put under the category of questionable penetration, this problem had been discussed many times in the literature and many published recommendations are there in the literature like using more advanced helical CT scan devices, using narrower slices of CT images reaching up to $1 \mathrm{~mm}$ thin slices and using special digital reformatting programs of the images to decrease metal artifact around titanium alloy based pedicle screws15 . although we were homogenous with many of these recommendations in our study but still we had complained of this problem and we have considered $5.73 \%$ of our inserted pedicular screws as being questionable. our relatively low rate of screw malposition in comparison to what is published in literature may be attributed to many factors: our sample of study is relatively small in number, the study is the result of a single surgical center, it may be attributed to the use of intraoperative fluoroscopy and experience level of the surgeons who performed the surgeries. Laine et al noted as $28.1 \%$ to $39.9 \%$ screw malposition rate in clinical studies and $5.5 \%$ to $31.3 \%$ malposition rate in cadaver studies 16 Ferrick et al reported accuracy rates of $73 \%$ to $83 \%$ in radiographic evaluation of pedicle screw placement in human cadaver lumbar spines17.Faber et al inserted 74 pedicle screws in 16 patients and evaluated the sensitivity of radiographic assessment of cortical perforation using CT scan as the gold standard; in their study 21/ 74 screws violated the medial cortex on CT scan despite of the performance of midline laminectomy to palpate the pedicle during screw insertion 12 . Laine et al studied pedicle screw placement in 30 low back pain patients with radiographs and $\mathrm{CT}$ scan. A total number of $32 / 152(21 \%)$ of screws perforated the 
pedicle cortex as judged by CT imaging 18 . Yoo et al reported accuracy ratio of $68 \%$ to $81 \%$ in the CT evaluation of pedicular screw placement in cadaver scans using the (in /out) criteria, increased accuracy occurred with titanium versus cobalt chromium screws, thought to be due to less CT scanning artifacts19. Pedicle penetration occurred more often in medial and lateral walls and less in superior and inferior walls, this is because of the anatomy of the pedicle20. In our study we found that out of 5 screws considered frankly misplaced, the incidence of medial and lateral cortical penetration was equal $2 / 5$ ( $40 \%$ ) for medial and $2 / 5$ ( $40 \%$ ) for lateral penetration, but we have no screws penetrated in superior or inferior direction. In a meta-analysis of the literature from 1996 until 2006 (130 studies involving a total of 37,337 pedicular screws inserted),kosmopoulous and schizas , found a mean misplacement rate of $8.7 \% 10$ Lonstein et al, reported a misplacement rate of $5.1 \% 21$, however, in these reviews the most common method of investigation was plain radiography, and the criteria for accuracy was ( in/out) criteria, additionally in many studies there is substantial variations in terms of type of population studied ( in vivo or in human cadavers), screw material and surgical experience level. In our study we tried to make these parameters homogenous as much as possible ,by making the surgeries done by experienced spine surgeons, using C-arm fluoroscopy to guide screw placement, using the same implant material as much as possible, interpretation of the post-operative scans by a radiologist and surgeons conducted the operations. Majority of our screws were between L3 and S1 $(63.9 \%)$, this may be partly attributed to that most of the cases with degenerative spinal disorders and spondylolithesis were mainly affecting these lower lumbar levels. The rate of neurological injury related to improper screw positioning has been reported to be as high as $11 \%$ and as low as $2 \%$ in the literature 22 .Weinatein et al , found that neurological dysfunction was associated with spinal canal penetration of $>6 \mathrm{~mm} 23$. Isley MR, et al in their work investigated the importance of intraoperative neuromonitoring for a safe pedicular screw placement24. Many recent studies proved the use of neuromonitoring as a strategy to reduce the incidence of malpotioning using recent advances and novel techniques 25 . As in our study, many clinical studies reported some cases of patients with screw penetration $<6 \mathrm{~mm}$ who demonstrated neurological deficit, and the incidence of neurological deficit, defined by the presence of sensory and or motor deficits or new radicular pain was seen in one case out of a total 25 cases (4\%).It is the case with moderate medial penetration at D11 vertebral level, in which the patient suffered of new onset back pain with radiation to the right lower limb, while we didn't report any neurological deficit in the other 4 cases of mild screw penetration.

\section{Conclusion:}

Pedicular screw insertion is relatively safe procedure with few complications in experienced hands.

The incidence of screw misplacement detected in our study is compatible with the lowest rates of misplacements published in literature.

Not all misplaced screws are associated with neurological deficit and this may be attributed to the direction and severity of cortical penetration.

\section{Authors' contributions:}

Saif M. Kani: Data collection and Manuscript writing.

Ali Bakir. Al-Hilli: Data collection and Manuscript writing.

Dawood S. Al-Obidi: Supervisor.

\section{References:}

1-James N. Weinstein, Bjorn L. Rydevik: anatomic and technical considerations of pedicle screw fixation. Clin Orthop Rel Res 1992; 284: 34-46.

2-Mark B. Kabins, James N. Weinstein : The history of vertebral screw and pedicle screw fixation. Iowa Orthop J. 1991; 11: 127-136.

3-Robert W. Gaines, Jr.: The Use of Pedicle-Screw Internal Fixation for the Operative Treatment of Spinal Disorders. J Bone Joint Surg Am, 2000 Oct 01; 82(10):1458-1458.

4-Amato V, Giannachi L, Irace C.: Accuracy of pedicle screw placement in the lumbosacral spine using conventional technique: computer tomography post operative assessment in 102 consequative patients. J Neurosurg Spine 12:306-313, March 2010.

5-Mulholland RC. Pedicle screw fixation in the spine [editorial]. J Bone Joint Surg Br 1994;76B: 517-19.

6-Scoliosis research society morbidity, mortality committee. Member survey, 1987.

7-Roy-camille, Saillant G. : internal fixation of the lumbar spine with pedicle screw plating. Clin Orthop 1986; 203: 7-17.

8-Weise L, Suess O, Picht T et al.: Transpedicular screw fixation in the thoracic and lumbar spine with a novel cannulated poly axial screw system. Medical Devices: Evidence and Research 1:33-39, 2008.

9-Acikbas SC,Arslan FY, Tuncer MR: the effect of transpedicular screw placement on late spinal stability. Acta neurochir (Wien) 145: 949-955,2003.

10-Kosmopoulos V, Schizas C.: Pedicle screw placement accuracy: a meta analysis. Spine ( Phila Pa 1976) 32:E111-E120,2007.

11-Amiot LP, Lang K, Putzier M.: Comparative results between conventional and computer-assisted pedicle screw installation in the thoracic, lumbar, and sacral spine. Spine ( Phila Pa 1976) 25: 606614, 2000.

12-Farber GL, Place HM, Mazur RA, et al.: accuracy of pedicle screw placement in lumbar fusions by plain radiographs and computed tomography. Spine 1995; 20: 1494-99. 
13-Kim YJ, Lenke LG, Cheh G.: Evaluation of pedicle screw placement in the deformed spine using intra operative plain radiographs: a comparison with computerized tomography. Spine ( Phila $\mathrm{Pa}$ 1976) 30: 2084-2088, 2005.

14-Castro WHW, Halm H, Jerosch J.: Accuracy of pedicle screw placement in lumbar vertebrae. Spine ( Phila Pa 1976) 21: 1320-1324, 1996.

15-Yeams JS, Chung MS, Leeck: reduction of metal artifact around titanium alloy-based pedicle screws on CT images: an approach using a digital image enhancement technique. J.korean soc spine surg. 2002 Dec; 9 (4): 280-288.

16-Austin MS, Vaccaro AR, Brislin B.: A cadaver study comparing open laminoforaminotomy and two image-guided tehniques for pedicle screw placement in posterolateral fusion and non fusion models. Spine ( Phila Pa 1976) 27: 2503-2508,2002.

17-Ferrick MR, Kowalski JM, Simmons ED.: Reliability of roentgenogram evaluation of pedicle screw position. Spine 1997; 22: 1249-53.

18-Laine T, Makitalo K, Schlenzka D.: Accuracy of pedicle screw insertion: aprospective CTstudy in 30 low back patients. Eur Spine J 6: 402-405,1997.

19-Yoo JU, Ghanayem A, Petersilge C.: Accuracy of using computed tomography to identify pedicle screw placement in cadaveric human lumbar spine. Spine 1997; 22: 2668-71.

20-Attar A, Ugur HC, Uz A.: Lumbar pedicle: surgical anatomic evaluation and relationships. Eur Spine J 10: 10-15, 2001.

21-Lonstein JE, Denis F, Perra JH. : Complications associated with pedicle screws. J Bone Joint Surg Am 81: 1519-1528, 1999.

22-Brown CA, Lenke LG, Bridwell KH.: Complications of pediatric thoracolumbar and lumbar pedicle screws. Spine ( Phila Pa 1976) 23: 1566-1571, 2002.

23-Weinstein JN, Spratt KF, Spenegler D, et al. Spinal pedicle fixation: reliability and validity of roentgenogram-based assessment and surgical factors on successful screw placement. Spine 1998; 13: 1012-18.

24- Isley MR, Zhang XF, Balzer JR, Leppanen RE. Current trends in pedicle screw stimulation techniques: Lumbosacral, thoracic, and cervical levels. Neurodiagn J. 2012 Jun;52(2):100-75.

25-Calancie B, Donohue ML, Moquin RR. Neuromonitoring with pulse-train stimulation for implantation of thoracic pedicle screws: a blinded and randomized clinical study. Part 2. The role of feedback. J Neurosurg Spine. 2014 Jun;20(6):692704. 